\title{
Como se formam os professores coordenadores na rede estadual de ensino de São Paulo? ${ }^{1}$
}

\author{
How are the coordinating teachers trained in the state educational \\ network of São Paulo?
}

\begin{abstract}
Rebeca Franciele Vera
Mestre em Educação Escolar, pela UNESP. Docente da Rede Municipal de Ensino de Lençóis Paulista rebecca_franciele@hotmail.com

Maria José da Silva Fernandes Doutora em Educação Escolar, pela UNESP. Docente do Programa de Pós-Graduação em Educação Escolar, UNESP/Araraquara, e do Departamento de Educação, UNESP/Bauru. mj.fernandes@unesp.br
\end{abstract}

Resumo: $\mathrm{O}$ artigo problematiza as ações formativas destinadas aos professores coordenadores (PC) na rede estadual de ensino de São Paulo. Os dados analisados decorrem de levantamento documental sobre formação continuada oferecida pela Secretaria Estadual, especialmente pela Escola de Formação de Professores (EFAP), no período de 2010 a 2018. Identificaram-se fragilidades nas ações formativas voltadas àqueles que, nas escolas, realizam a formação continuada de professores. Há predomínio de ações de curta duração, na modalidade à distância, organizadas numa perspectiva tradicional e desarticuladas da organização pedagógica coletiva das escolas.

Palavras chaves: Professores coordenadores. Formação continuada. Rede estadual de ensino de São Paulo.

\begin{abstract}
The article problematizes the formative actions destined to coordinating teachers (PC) in the state education network of São Paulo. The data analyzed are based on a documentary survey on continuing education offered by the State Secretariat, especially by the School of Teacher Training (EFAP), from 2010 to 2018. Fragilities have been identified in the training actions directed at those who in the schools carry out the continuous training of teachers. There is a predominance of short duration actions, in the distance modality, organized in a traditional perspective and disarticulated of the collective pedagogical organization of the schools.
\end{abstract}

Keywords: Coordinating teachers. Continuing education. State Education network of São Paulo. 


\title{
Introdução
}

O movimento de democratização do ensino, ocorrido entre a segunda metade da década de 1980 e o início dos anos 90, possibilitou maior envolvimento e desenvolvimento profissional dos trabalhadores da educação, bem como a valorização da escola como lócus de decisão e formação continuadaii. No estado de São Paulo, em especial, a função iii de coordenação pedagógica ganhou destaque e abrangência a partir de 1996. Em meio à discussão sobre superação do fracasso escolar, gestão democrática, elaboração do Projeto Político Pedagógico e formação centrada na escola, atendeu-se antiga reivindicação da categoria docente que desde décadas anteriores lutava pelo trabalho de articulação coletiva e organização pedagógica da escola (FERNANDES, 2008).

O trabalho relativo à coordenação pedagógica é dotado de especificidades em relação a outros profissionais que atuam na gestão escolar, tais como o diretor e o vicediretor. Trata-se de função de natureza eminentemente pedagógica que, além de se responsabilizar por complexas atribuições relacionadas à articulação do trabalho coletivo e à organização pedagógica da escola, também realiza a formação continuada do grupo de professores (PINTO, 2011), realizada na rede estadual durante as Aulas de Trabalho Pedagógico Coletivo (ATPC).

Entretanto, a natureza pedagógica da função de coordenação vem se alterando ao longo dos anos. Inicialmente prevista nos Estatutos do Magistério ${ }^{i v}$ - Lei no 114/74 e $\mathrm{n}^{\circ} 444 / 85$ - e detalhada em resoluções publicadas posteriormente, caso da Resolução n ${ }^{\circ}$ 28/1996, a função assumiu novos delineamentos e atribuições que a afastaram do âmbito pedagógico, aproximando-a do controle e gerenciamento das reformas educacionais (FERNANDES, 2018)

\begin{abstract}
A função eminentemente articuladora e voltada para o exercício de atividades pedagógicas relacionadas às necessidades específicas das escolas foi apropriada com outros objetivos e intenções ao longo de vários anos de implantação de uma perniciosa política educacional gerencialista e performática. Por meio de diferentes resoluções, a coordenação pedagógica foi vinculada a formas tradicionais e burocráticas de administração escolar, embora disfarçadas sob um discurso democrático e autônomo. Os aspectos legais conduziram a função para o controle e monitoramento docente, assumindo múltiplas tarefas que alteraram, em nome de uma suposta qualidade, a natureza do trabalho e fragilizaram sua identidade.
\end{abstract}

Para a autora supracitada, as atribuições voltadas especificamente à articulação do trabalho coletivo, à organização da escola e à formação continuada, esta última uma das marcas identitárias do trabalho de coordenação pedagógica, foram legalmente se esgarçando, e o PC, ao assumir outras tarefas, distanciou-se da natureza eminentemente 
pedagógica, o que em São Paulo, evidenciou-se até mesmo na denominação da função que perdeu o atributo "pedagógico" (FERNANDES, 2012).

As exigências legais para aqueles que desejavam atuar como professor coordenador mantiveram-se praticamente iguais nas resoluções oficiais desde a expansão da função. De acordo com a Resolução SE $\mathrm{n}^{\circ} 75 / 14 \mathrm{v}$, os três requisitos mínimos para a ocupação da função contemplam a vinculação docente à rede estadual de ensino, ter licenciatura plena e experiência docente mínima de três anos no magistério público estadual. A formação inicial do PC é fator que tem impacto no trabalho, como já discutido por Placco (2002: 97-98):

\begin{abstract}
Sem entrar no mérito da formação do próprio coordenador pedagógico (seja no âmbito dos cursos de pedagogia, seja no âmbito dos cursos de licenciatura de que são oriundos os chamados professores coordenadores pedagógicos), podemos nos referir às análises críticas que têm sido realizadas quanto à formação dos docentes, nas quais ficam claras não apenas a precariedade de sua formação em sua área específica de conhecimento, mas também a marcante precariedade de sua formação pedagógica, no que tange à compreensão do sistema de ensino, do processo de ensino e aprendizagem dos alunos pelos quais serão responsáveis.
\end{abstract}

Pinto (2011) também faz uma discussão sobre a importância da formação pedagógica sólida para aqueles que atuam nos processos educativos escolares a partir das atividades de coordenação pedagógica:

O pedagogo escolar como profissional da Educação que atua nas escolas, fora da sala de aula, tem de pautar sua ação a partir de uma sólida formação pedagógica. Porém, se a Pedagogia desenvolve-se historicamente a partir dos estudos sobre os processos de ensino e aprendizagem que ocorrem na sala de aula, pode parecer desnecessário exigir do profissional que atuará fora da sala de aula sólida formação pedagógica. Porém, o entendimento de que a Pedagogia desenvolve-se a partir do exercício da docência não implica em reduzi-la a essa esfera do pedagógico (PINTO, 2011:75-76).

Sendo o PC um licenciado em diversas áreas do conhecimento, que pode ter, como indicado por pesquisas anteriores (GATTI, 2008), marcas de precariedade e ausência de formação pedagógica sólida, podem ocorrer dificuldades para realizar a necessária formação continuada de outros professores. Esta era uma preocupação já anterior, uma vez que Fusari (2009), em artigo sobre os fatores que intervêm na atuação do coordenador pedagógico, questionou: “Quem forma o formador?”. Christov (2001) também já abordou a questão da formação dos PCs:

Para o exercício desta função, não é exigida a formação em Pedagogia: muitos coordenadores são professores de matemática ou educação física, sem acúmulo de reflexão sobre questões educacionais mais gerais ou de didática em particular. Se, por um lado, é interessante que todos os professores possam vivenciar esta 
experiência de coordenação, mesmo sem a formação pedagógica, por outro, muitos coordenadores queixaram-se da ausência de um projeto da Secretaria da Educação voltado especificamente para o preparo dos coordenadores pedagógicos quanto aos temas do âmbito da Pedagogia (CHRISTOV, 2001:120121).

Fernandes (2004) buscou referências sobre a formação dos PCs no momento em que esta foi expandida para a rede pública estadual. A autora indicou que naquele momento houve grande preocupação por parte da APEOESP com a formação dos professores que ocupavam a função. $\mathrm{O}$ sindicato, tendo em vista uma concepção mais ampla de formação profissional e de transformação da escola, ofereceu aos professores um curso específico para atuação na função que teve como epicentro a escola e a prática pedagógica, buscando expandir o domínio de uma área específica do conhecimento:

\begin{abstract}
Se o fato de "conhecer o terreno" onde atuará permite ao professorcoordenador uma inserção mais orgânica na vida da escola, é preciso lembrar que, agora, sua ação ocorrerá numa perspectiva diferente daquela de professor. Até então cabia-lhe, como bom profissional, o domínio de sua área específica; o desenvolvimento competente das atividades docentes; a busca de articulações do seu trabalho com o de outras áreas afins; o bom relacionamento com os alunos; preocupando-se com as soluções de suas dificuldades e, ainda, contribuir com o bom andamento do coletivo escolar no sentido de garantir a realização de um bom ensino. Sem dúvida, essas atribuições constituem a base de formação de identidade do professor que, ano após ano, vai sendo constituída no processo de vivência profissional. E é nesse processo, que é pessoal e único, que ele estabelece seus compromissos sociais e profissionais e forma seu "olhar de professor". Isso caracterizou até o momento a vivência do professorcoordenador.

$\mathrm{Na}$ nova função, ter presente o olhar de professor sobre as necessidades da escola será uma referência fundamental para sua atuação, mas um passo além precisa ser dado. Agora será necessário uma compreensão da totalidade dessa realidade escolar, capaz de apreender os locais e os momentos onde uma precisa intervenção pode desatar os nós e agilizar o trabalho. Em suma, estamos dizendo que ser professor-coordenador é diferente de ser professor (SÃO PAULO, 1996: p. 8).
\end{abstract}

Considerando este contexto no qual um professor com formação específica, advindo de diferentes áreas do conhecimento, tem entre suas atribuições a formação continuada dos pares, agregada a outras de natureza gerencial, nos sentimos instigadas a investigar a formação continuada destinada aos PCs na rede pública estadual paulista de ensino regular. Ou seja, buscamos responder um questionamento já apontado na literatura anos atrás: quem forma o formador? A este questionamento, agregamos outros: como se forma o formador? Como a SEE/SP se ocupa desta tarefa de formação? Como se constitui a formação continuada voltada aos PCs na rede paulista?

Para responder tais questionamentos, selecionamos para análise a legislação específica sobre a formação continuada na rede - Resoluções publicadas na página da SEE/SP - bem como documentos oficiais da Escola de Formação de Professores (EFAP) 
e suas ações formativas no período de 2010 a 2018. Esta análise foi antecedida pela breve descrição da trajetória metodológica.

\section{A Formação Continuada na Rede Estadual Paulista: análise das ações formativas}

É possível inferir que a fragilidade na formação dos PCs seja uma consequência da própria legislação, que não exige conhecimentos pedagógicos específicos para aqueles que desejam atuar na função. Por outro lado, a análise documental nos permitiu afirmar que a previsão de ações de formação continuada a serem oferecidas regularmente aos PCs, especialmente aos que iniciam no trabalho, é incipiente e marcada pela descontinuidade dos projetos, demonstrando ausência de uma política própria de formação por parte da SEE/SP.

Até mesmo do ponto de vista da pesquisa acadêmica, poucas são as que se relacionam especificamente à formação continuada do coordenador pedagógico, havendo grande destaque às ações voltadas aos professores. Em levantamento realizado, por exemplo, na principal base de dados do país - Coordenação de Aperfeiçoamento de Pessoal de Nível Superior (CAPES) - localizamos apenas nove pesquisas no período de 2011 a 2014 sobre a formação continuada dos coordenadores pedagógicos, sob suas diferentes denominações (orientador pedagógico, professor coordenador, professor coordenador pedagógico, supervisor pedagógico).

A fim de analisar os documentos legais que orientaram a formação continuada dos ocupantes da função de coordenação pedagógica, recorremos à página oficial da Secretaria da Educação do Estado de São Paulo. Neste espaço, localizamos, além das resoluções relacionadas ao processo de escolha e trabalho do PC, sete resoluções específicas sobre formação continuada. Dentre elas, selecionamos para análise as duas que tratavam especificamente das atividades centralizadas na Escola de Formação e Aperfeiçoamento dos Professores do Estado de São Paulo - EFAP e das Orientações Técnicas (OTs) realizadas pelos órgãos regionais representados pelas Diretorias de Ensino, sendo estes dois grupos correspondentes às principais ações oficiais de formação.

De acordo com a Resolução SE no 61/2012, as Orientações Técnicas correspondem a atividades propostas tanto pelos órgãos centrais como regionais com duração mínima de quatro e máxima de oito horas, que podem ser realizadas em horário regular de trabalho, e que apresentem caráter pontual, sistemático ou circunstancial. Tais atividades têm como objetivo subsidiar "a atuação de servidores na implementação de 
diretrizes, metodologias, procedimentos e/ou práticas técnico-pedagógicas, curriculares e administrativas da educação básica”, visando o aperfeiçoamento do desempenho (São Paulo, 2012).

As OTs, consideradas como atividades de formação no âmbito da rede estadual, prestam-se mais à transmissão de recados e organização de ações de trabalho no cotidiano escolar. Pela própria definição oficial, não têm caráter longitudinal e contínuo, apresentando-se como frágeis momentos de apropriação de conhecimentos e desenvolvimento profissional. Pelo que é indicado na estrutura da rede, podemos também inferir que têm frágeis contribuições para a construção da autonomia intelectual (CHRISTOV, 2004). As OTs, pela dispersão das ações, remetem aos treinamentos anunciados e criticados por Marin (1995). Para a autora, o termo "treinamento" é recorrente na educação e utilizado como forma de "tornar destro, apto, capaz de determinada tarefa" (p.15). Nesta perspectiva, as OTs podem ter finalidades meramente mecânicas voltadas à modelagem de comportamentos que anseiam por ações padronizadas, muitas das quais compreendidas no contexto atual como "competências".

Já a EFAP, criada em 2009, integra o Programa Mais Qualidade na Escolavi que considera a formação permanente e continuada dos profissionais da educação como um dos pilares para melhoria da qualidade de ensino. A EFAP, segundo a Resolução n58/2011 (SÃO PAULO, 2011) se destina à realização de ações de formação realizadas por meio de cursos e programas, considerando-se cursos como:

\footnotetext{
ciclos de palestras e de estudos, congressos, conferências, simpósios, encontros, fóruns, seminários, oficinas e videoconferências, realizados no país ou no exterior, presenciais ou a distância, que disponham sobre determinada unidade temática integrante de um conjunto previamente definido e estruturado (SÃO PAULO, 2011).
}

Os cursos de atualização, segundo a mesma Resolução, devem ser desenvolvidos tanto pela EFAP, em vista das necessidades e demandas diagnosticadas, como também por instituições e entidades conveniadas (Instituição de Ensino Superior, Entidades representativas das Classes do Magistério, Instituições públicas, privadas e não estatais), com duração igual ou superior a 30h. Na análise das ações formativas é nítida a participação de instituições privadas, tais como Fundação Santillana e Instituto ABCD, evidenciando as parcerias público-privadas que têm marcado a educação paulista nas últimas décadas. Outra característica da EFAP é a oferta de cursos que combinam 
atividades no Ambiente Virtual de Aprendizagem (AVA-EFAP) com atividades presenciais e em serviço nas Diretorias de Ensino.

Ao fazer um levantamento na página oficial EFAP identificamos quais os cursos oferecidos por esse órgão no período de 2010, quando começaram efetivamente suas atividades, a 2018. Os cursos foram identificados como "em andamento", "encerrado" e com "inscrições abertas". No período em que realizamos o levantamento foi possível obter informações de 46 cursos encerradosvii. "Em andamento" foram localizados cinco cursos, enquanto que com "inscrições abertas" encontramos apenas um. Desse total de 52 cursos, apenas 16 deles não tiveram uma segunda edição oferecida pela EFAP. Dos 52 cursos selecionamos para análise apenas os que incluíam o PC como um dos sujeitos dentre o público a quem se voltava a formação, o que totalizou 41 cursos. Dentre os 41 cursos selecionados, não havia nenhum deles voltado específica e exclusivamente aos PCs, sendo normalmente abertos aos professores de maneira geral, e, em alguns casos, aos demais integrantes do trio gestor da escola.

Organizamos os cursos selecionados, a partir de seus títulos, em eixos temáticos: gestão democrática (8), processos de ensino e aprendizagem em conteúdos específicos, tais como matemática (7), desenvolvimento profissional (6), tecnologias digitais e uso das TICs (7), educação inclusiva (6), currículo (2), inglês (2), avaliação (1), segurança na escola (1), gênero, sexualidade e diversidade (1). A partir da análise dos temas e dos conteúdos dos cursos, podemos afirmar que tratam de temáticas pontuais e esparsas. Os cursos não tinham uma continuidade, contrariando a própria legislação que exige que os mesmos sejam "integrantes de um conjunto previamente definido e estruturado" (São Paulo, 2011). No documento intitulado Regulamento, do qual os dados foram extraídos, não havia também indicação do referencial bibliográfico dos diferentes cursos.

Para Marin (1995), a formação deve acontecer na perspectiva de uma educação continuada, devendo possibilitar que os envolvidos conheçam, analisem, critiquem, aceitem ou não as ideias promovidas pelas ações das quais participam. A formação continuada, segundo Marin (1995), tem como significado fundamental a atividade conscientemente proposta e direcionada para a mudança. Ou seja, corresponde a um conjunto de ações elaboradas com a finalidade de contribuir para o desenvolvimento dos sujeitos envolvidos, mas que para isso levam em consideração as especificidades e as necessidades do grupo. A análise, portanto, nos levou a identificar uma perspectiva ainda tradicional de formação, pautada em cursos desarticulados, sem continuidade, definidos verticalmente e sem condições para que o pensamento crítico se efetivasse. 
A leitura do rol de conteúdos ministrados pelos 41 cursos possibilitou identificar que eles eram direcionados a diversos aspectos que tangenciam a atuação do PCs e o apoio que estes podem oferecer aos professores em sala de aula, tais como: a gestão escolar e a gestão de sala de aula, a administração do tempo, a gestão na dimensão pedagógica, a observação em sala de aula, currículos e avaliação. Entretanto, a mesma formação destinada aos professores era ofertada aos PCs, não havendo um conteúdo mais denso que pudesse ser explorado ou que servisse de base formativa para novas ações que pudessem ser realizadas nas escolas. Sem articulação entre os cursos e sem conteúdos que possibilitassem a construção de uma identidade profissional, os cursos pareciam voltar-se mais a uma perspectiva de acumulação de pontos para progressão na carreira do que para o desenvolvimento profissional.

Nóvoa (1997) defende que a formação continuada não se constrói por acumulação de cursos, conhecimentos ou técnicas, mas, sim, por meio de um trabalho de reflexividade crítica sobre as práticas e (re)construção permanente de uma identidade profissional. Em outra publicação de 2002, o autor defende uma formação continuada centrada na investigação e na reflexão, devendo ser as iniciativas bem estruturadas a fim de que os objetivos das ações sejam de fato alcançados e passíveis de serem articuladas com as práticas realizadas nas escolas.

Também é possível inferir que as temáticas tenham sido determinadas pelos órgãos centrais e regionais, a partir de convênios realizados entre instituições externas e a SEE/SP. Não há evidências de que as demandas das escolas tenham sido a variável determinante na definição dos temas. É importante registrar que Gatti (2008, p. 59), apoiando-se em pesquisas anteriores, argumentou que as "capacitações" mais bem sucedidas no estado de São Paulo "foram resultantes de processos de negociação cuidadosa ente as instituições e as diretorias de ensino e que envolveram mais atores no processo (diretores, professores, técnicos)", o que não parece ser a perspectiva de formação adotada atualmente. Além disso, ao tomarmos como ponto de partida as atividades de formação oferecidas pela EFAP, verificamos que elas consideram superficialmente as demandas das escolas, aspecto criticado por Nóvoa (2002), Marin (1995) e Gatti (2008), assim como reduzem os espaços para discussão e troca entre os pares, dificultando o enriquecimento da prática que traz evidentes contribuições para o exercício da função (NÓVOA, 2002; FUSARI, 2009).

Nóvoa (2002) afirma que, ao longo dos anos, as ações formativas assumiram quase sempre um caráter pontual e disperso. Segundo ele, as formações baseiam-se na lógica do desenvolvimento do sistema educativo e não no desenvolvimento do docente e/ou da 
escola, reforçando a ideia de que as autoridades usam esses momentos para impor a lógica de preparação dos professores à "novidade" que desejam desenvolver na referida rede de ensino, o que se evidenciou nos cursos analisados.

Quanto às cargas horárias dos cursos, percebemos que estas eram, na maioria das vezes, reduzidas: 16h (1)viii; 20h (1); 30h (4); 32h (1); 40h (5); 45h (1); 40 /60h (1); 60h (11); 78h (1); 80h (2); 90h (7); 100h (2); 120h (1); 143h (1); 260h (1) e 444/686h (1). Ou seja, mais de $85 \%$ estavam na faixa de 16 a $90 \mathrm{~h}$ e apenas seis cursos na faixa de 100 a 686hix.

Dos 41cursos analisados, 26 deles eram autoinstrucionais, ou seja, não tinham nenhum tutor que auxiliasse nas tarefas ou que acompanhasse os fóruns de debates. O diálogo entre os pares é limitado quando as atividades formativas são realizadas à distância - com pequena interlocução entre os pares e frágil acompanhamento dos tutores - ou mesmo na modalidade semipresencial com um encontro mensal. Assim, podemos inferir que os cursos cumprem uma formação pontual e não continuada como se propõem os cursos da EFAP, tendo uma função mais de treinamento e capacitação do que de formação continuada.

Em relação ao tempo destinado às atividades formativas, verificamos que a carga horária semanal de trabalho do PC (40 horas semanais) é um agravante para a não participação em outras formas de estudo para além daquelas que ocorrem em seu horário de trabalho (caso das OTs). O PC teria que disponibilizar outras horas semanais para o estudo e reflexão entre os pares, deixando de usufruir de momentos de lazer e descanso com a família, que também são necessários para um trabalho satisfatório. Fusari (2009) defende que os professores deveriam ser contratados e remunerados para uma jornada de trabalho que permitisse a docência e também incluísse um tempo para atividades pedagógicas (planejamento, reuniões) e atividades de formação contínua em serviço na própria escola e fora dela, o que não ocorre atualmente com os PCs. O espaço formativo dentro da escola (que geralmente ocorre durante os ATPCs ou HTPCs dependendo da rede) traz, de acordo com o autor, contribuição para os envolvidos, mas, ao se deslocarem para outros espaços de formação e analisarem a realidade na relação com outros pares que apresentam as mesmas angústias, problemas e atribuições, as experiências formativas podem ser mais enriquecedoras. Neste sentido, para o autor, são necessários processos de formação organizados pelas redes de ensino nos quais sejam articuladas ações internas e externas à escola, sendo oferecidas condições para que os PCs se formem e formem os 
docentes sob sua responsabilidade, durante a jornada de trabalho para a qual são contratados.

Partindo da evidência de sobrecarga de trabalho na função de PC (FERNANDES, 2009), é de supor que os ocupantes da função pouco participem dos cursos ofertados pela EFAP, pois a realização de atividades exigiria um tempo não existente no cotidiano escolar, ocupando, portanto, outras dimensões da vida do profissional. Os PCs e os professores precisam realizar a maior parte das atividades de formação fora do horário de trabalho, sendo este um obstáculo para que as realizem de forma satisfatória.

Ainda podemos afirmar que as cinco teses levantadas por Nóvoa (2002) sobre a formação continuada - a formação contínua deve estar articulada com o desempenho profissional dos professores, tomando-se as escolas como lugares de referência; valorizar as atividades de auto formação participada e de formação mútua; refletir na prática e sobre a prática, valorizando os saberes dos quais os professores são portadores; ser protagonistas nas diversas fases do processo de formação - concepção, acompanhamento, regulação e avaliação; investir nas iniciativas já consolidadas pelos docentes ao invés de desconsiderálas e instaurar novos dispositivos de controle e de enquadramento - não se concretizaram na maior rede estadual de ensino regular do Brasil. Esse fato pode estar repercutindo diretamente nas ações desenvolvidas pelos PCs nas escolas, já que estão sendo guiados por múltiplas ações desarticuladas entre si sem a possibilidade concreta de refletir sobre a função e sua identidade profissional.

A literatura selecionada nos levou a questionar o atual contexto de formação continuada oferecido aos PCs (e seus possíveis reflexos na formação docente). Neste caso, em especial, percebeu-se que a importância atribuída pelos autores aos sujeitos que participam da formação continuada, com voz ativa durante todo o processo formativo e de partilha de saberes e a valorização dos processos de negociação entre as instituições e os atores, segue sendo pouco considerada e é, muitas vezes, marcada por embates entre as denominadas "ideias inovadoras" e a prática escolar, as políticas oficiais e as avaliações externas como norteadoras das formações oferecidas.

\section{Considerações finais}

O presente artigo teve por objetivo apresentar e problematizar algumas das ações formativas que foram ofertadas aos PCs na rede estadual paulista, entre os anos de 2010 e 
2018, podendo-se afirmar que nem as OTs e nem os cursos da EFAP atendem às especificidades da função de PC.

Conforme mencionado anteriormente, a formação inicial não tem oferecido condições de capacitar o docente para atuar na gestão, dadas suas fragilidades até mesmo para formar nas áreas específicas do conhecimento. Assim, a rede de ensino paulista, frente à possibilidade de atuação dos professores na coordenação pedagógica, deveria se responsabilizar pela oferta adequada de formação continuada e em serviço aos ocupantes da função. Ao analisar a maior rede de ensino do Brasil, verificamos que, apesar de existir uma legislação referente tanto ao trabalho do PC como à formação continuada, não há uma política explícita de formação, o que resulta em cursos pontuais e sem continuidade. Com públicos diversos, cursos à distância, sem mediação de tutores e sem explicitação dos referenciais teóricos que serão explorados, a formação continuada dos PCs torna-se bastante frágil.

Analisando as ações de formação oferecidas aos PCs - em suas duas modalidades centrais - identificamos predomínio de práticas tradicionais que há tempos são criticadas pela literatura, nas quais as ações são padronizadas, distantes das escolas e inibidoras da participação satisfatória e articulada dos sujeitos envolvidos. De nada adianta os PCs realizarem todos os cursos propostos pela EFAP sem que haja momentos propícios e específicos para a reflexão sobre a função e sua constituição identitária. Conclui-se que uma rede de ensino, para desenvolver um programa de formação continuada satisfatório, deva ter um plano de ação específico para o público ao qual se destina, no caso a coordenação pedagógica, possibilitando a relação com o cotidiano escolar e a possível melhoria na atuação do PC na formação docente.

\section{Referências}

CHRISTOV, Luiza Helena da Silva. Educação Continuada: função essencial do coordenador pedagógico. In: GUIMARÃES, Ana Archangelo; MATE, Cecília Hanna; BRUNO, Eliane Bambini Gorgueira et al. O coordenador pedagógico e a educação continuada. $7^{\text {a }}$ ed. São Paulo: Edições Loyola, 2004.

CHRISTOV, Luiza Helena da Silva. Sabedorias do coordenador pedagógico: enredos do interpessoal e de (con) ciências na escola. 2001, 162 f. Tese (doutorado em Psicologia da Educação) Pontifícia Universidade Católica, São Paulo.

FERNANDES, Maria José da Silva. Problematizando o trabalho do professor coordenador pedagógico nas escolas públicas paulistas. Araraquara, 2004. 113 p. Dissertação (Mestrado em Educação 
Escolar) - Faculdade de Ciências e Letras, Campus de Araraquara, Universidade Estadual Paulista "Júlio de Mesquita Filho".

FERNANDES, Maria José da Silva. A coordenação pedagógica em face das reformas educacionais paulistas: o trabalho desvelado. Araraquara, 2008. 282 p. Tese (Doutorado em Educação Escolar) - Faculdade de Ciências e Letras, UNESP - Campus Araraquara.

FERNANDES, Maria José da Silva Formação contínua de educadores na escola e em outras situações. In: BRUNO, Eliane Bambine Gorgueira; ALMEIDA, Laurinda Ramalho de; CHRISTOV, Luiza Helena da Silva (Org.). O coordenador pedagógico e a formação docente. São Paulo: Edições Loyola, 2009.

FERNANDES, Maria José da Silva. O professor coordenador pedagógico nas escolas estaduais paulistas: da articulação pedagógica ao gerenciamento das reformas educacionais. In: Educação e Pesquisa, São Paulo, v. 38, n.04, p.799-814, out./dez. 2012.

FERNANDES, Maria José da Silva. Da articulação do trabalho coletivo ao controle do trabalho docente: os (des)caminhos legais da Coordenação Pedagógica no Estado de São Paulo. In: Comunicações Piracicaba, v. 25, n. 3, p. 67-80, set.-dez. 2018

FUSARI , José Cerchi. Formação contínua de educadores na escola e em outras situações. In: BRUNO, Eliane Bambine Gorgueira; ALMEIDA, Laurinda Ramalho de; CHRISTOV, Luiza Helena da Silva (Org.). O coordenador pedagógico e a formação docente. São Paulo: Edições Loyola, 2009.

GATTI, Bernardete Angelina. Análise das políticas públicas para formação continuada no Brasil, na última década. In: Revista Brasileira de Educação, São Paulo, v. 13, n. 37 jan./abr. 2008.

MARIN, Alda Junqueira. Educação Continuada: introdução a uma análise de termos e concepções. Caderno CEDES. Campinas. São Paulo: Papirus, n.36, 1995.

NÓVOA, Antonio. Concepções e práticas de formação contínua de professores. IN: NÓVOA, Antonio. Formação de Professores e Trabalho Pedagógico. Lisboa: Educa, 2002.

NÓVOA, Antonio. Formação de professores e profissão docente. IN: NÓVOA, A (org.). Os professores e a sua formação. Lisboa: Nova Enciclopédia, 1997 . Disponível em: $<$ http://repositorio.ul.pt/bitstream/10451/4758/1/FPPD_A_Novoa.pdf $\geq$. Acesso em 15 de novembro de 2016.

PINTO, Umberto de Andrade. Pedagogia escolar: coordenação pedagógica e gestão educacional. São Paulo: Cortez, 2011.

PLACCO, Vera Maria Nigro de Souza; ALMEIDA, Laurinda Ramalho de.; SOUZA, Vera Lúcia Trevisan de. O coordenador pedagógico e a formação de professores: intenções, tensões e contradições. Estudos \& Pesquisas Educacionais nº. 2. São Paulo: Fundação Victor Civita, 2011.

PLACCO, Vera Maria Nigro de Souza; ALMEIDA, Laurinda Ramalho de.; SOUZA, Vera Lúcia Trevisan de. Formação de professores: o espaço de atuação do coordenador pedagógico-educacional. In: AGUIAR, Márcia Ângela da Silva; FERREIRA, Naura Syria 
Carapeto (orgs.). Para onde vão a orientação e a supervisão educacional? Campinas/SP: Papirus, 2002.

SÃO PAULO. Resolução SE 28, de 4 de abril de 1996. Dispõe sobre o processo de seleção, escolha e designação de docente para exercer as funções de Professor Coordenador, em escolas da rede estadual de ensino e dá providências correlatas.

SÃO PAULO. Resolução SE 58, de 23 de agosto de 2011. Dispõe sobre a oferta e o desenvolvimento das atividades didáticas previstas no Regimento Interno da Escola de Formação e Aperfeiçoamento dos Professores do Estado de São Paulo - EFAP, aprovado pelo Decreto $n^{\circ}$ 56.460, de 30.11.2010. Disponível em:

<http://siau.edunet.sp.gov.br/ItemLise/arquivos/58_11.HTM?Time=10/10/2011\%2011: 44:45\%20PM>. Acesso em 15 de maio de 2015.

SÃO PAULO. Resolução SE 61, de 6 de junho de 2012. Dispõe sobre Orientações Técnicas realizadas pelos órgãos centrais e regionais, de que trata o artigo $8^{\circ}$ da Resolução SE 58, de 23.8.2011. Disponível em: <

http://siau.edunet.sp.gov.br/ItemLise/arquivos/61_12.HTM?Time=05/01/2017\%2022:3 6:42>. Acesso em 15 de maio de 2015.

VERA, Rebeca Franciele. A formação continuada do professor coordenador na rede pública estadual paulista de ensino regular. Araraquara, 2017.116p. Dissertação (Mestrado em Educação Escolar) - Faculdade de Ciências e Letras, Campus de Araraquara, Universidade Estadual Paulista "Júlio de Mesquita Filho".

Recebido em: 29 abr. 2019 / Aprovado em: 30 out. 2019

\section{$\underline{\text { Cite como }}$}

VERA, Rebeca Franciele; FERNANDES, Maria José da Silva. Como se formam os professores coordenadores na rede estadual de ensino de São Paulo. Dialogia, São Paulo, n. 33, p. 5-18, set./dez. 2019. Disponível em: https://doi.org/10.5585/Dialogia.n33.13612.

\footnotetext{
${ }^{1} \mathrm{O}$ artigo é um recorte da dissertação intitulada Formação Continuada do Professor Coordenador na rede pública estadual paulista de ensino regular realizada junto ao Programa de Pós Graduação em Educação Escolar da Universidade Estadual Paulista Júlio de Mesquita Filho, Campus Araraquara, defendida em $16 / 02 / 2017$.

${ }^{2}$ De acordo com Gatti (2008), sob o "guarda-chuva do termo educação continuada” apareceram, após a segunda metade da década de 1990, um grande e variado número de iniciativas voltadas ao aprimoramento profissional docente, tratando-se de um universo amplamente heterogêneo quanto à estrutura adotada e duração temporal prevista.

${ }^{3}$ Faremos neste artigo referência ao trabalho do coordenador pedagógico como função, já que esta é a denominação adotada na rede estadual paulista. Diferente de cargo, a função é sempre uma ocupação temporária porque não está atrelada à realização de um concurso público de ingresso e efetivação. O acesso a uma função se dá através de designações, ou seja, autorizações para que um docente titular ou
} 
ocupante de função atividade (OFA) realize temporariamente atividades previstas no Estatuto do Magistério (FERNANDES, p.54, 2004).

${ }^{4}$ É importante registrarmos que em trabalho publicado por Fernandes (2004), apontou-se que as experiências iniciais com a coordenação pedagógica em São Paulo surgiram em décadas anteriores (final anos 50 e início da década de 1960) vinculadas a projetos específicos da SEE/SP, tais como as Escolas Experimentais, os Colégios Vocacionais e as Escolas de Aplicação.

${ }^{5}$ A Resolução é até o presente momento o documento oficial que define os requisitos para a função. Alguns artigos foram alterados por resoluções posteriores, mas não alteraram as exigências mínimas para os PCs.

${ }^{6}$ Programa lançado pelo governador José Serra e pelo então secretário de Estado da Educação, Paulo Renato Costa Souza, que visava contribuir para a melhoria da qualidade do ensino público de São Paulo.

${ }^{7}$ Outros 41 cursos encerrados não foram analisados por não termos acesso ao conteúdo dos mesmos.

${ }^{8}$ Carga horária seguida pelo número de cursos relacionados à mesma.

${ }^{9}$ Referente a curso de especialização em parceria com a UNESP. 